\title{
Calcium Transport Abnormality in Uremic Rat Brain Synaptosomes
}

\author{
Cosmo L. Fraser, Philip Sarnacki, and Allen I. Arieff \\ Division of Nephrology, Department of Medicine, Veterans Administration Medical Center, \\ and University of California, San Francisco, California 94121
}

\begin{abstract}
Brain calcium is elevated in patients and laboratory animals with uremia. The significance of this finding is unclear. We evaluated calcium transport in brain of both normal and acutely uremic rats (blood urea nitrogen $=250 \mathrm{mg} / \mathrm{dl}$ ) by performing studies in synaptosomes from rat brain cerebral cortex. Synaptosomes are vesicular presynaptic nerve endings from brain that contain mitochondria and are metabolically active. Two mechanisms of calcium transport were evaluated using radioactive ${ }^{45} \mathrm{Ca}^{++}$as a tracer. Both mechanisms were evaluated in the absence of exogenously administered parathyroid hormone (PTH). We first evaluated $\mathrm{Na}^{+}-\mathrm{Ca}^{++}$exchange in vesicles that were loaded with $\mathrm{NaCl}$ in an external media containing $10 \mu \mathrm{M} \mathrm{CaCl}$. Both initial rates of calcium transport and equilibrium levels of calcium accumulation in synaptosomes prepared from uremic rats were significantly greater $(P<0.005)$ than in normal. To assess calcium efflux, ATP-dependent calcium uptake (1 mM ATP) was studied in inverted plasma membrane vesicles loaded with $\mathrm{KCl}$. In the uremic synaptosomes, a significant increase $(P<0.005)$ in ATP-dependent calcium uptake was observed as compared with the normal. These studies show that (a) Calcium accumulation via the $\mathrm{Na}^{+}-\mathrm{Ca}^{++}$exchanger is increased in synaptosomes prepared from uremic rat brain. (b) Calcium influx into inverted plasma membrane vesicles from uremic rats via the ATP-dependent calcium transport mechanism is increased when compared with normal. (c) The increased calcium accumulation in uremia by both $\mathrm{Na}^{+}-\mathrm{Ca}^{++}$exchange and ATP-dependent calcium transport mechanism appears to be a result of increased synaptosomal membrane permeability to calcium. Both these abnormalities of calcium transport in uremia would tend to increase brain extracellular calcium in vivo. The defects observed in uremia do not appear to be readily reversible, and the relationship to PTH is presently unclear. These abnormalities may affect neurotransmission in the uremic state.
\end{abstract}

\section{Introduction}

Brain cell calcium is elevated in patients and laboratory animals with uremia and is associated with alterations in the electroencephalogram $(1,2)$. The functional significance of this finding is unclear, but it may relate to neurotransmission, as neurotransmitter release into the synaptic space in nerve terminals in

This paper was presented in part at the annual meeting of the American Society of Nephrology, Washington, DC, 1984.

Dr. Fraser was a National Kidney Foundation Research Fellow and is presently an Associate Investigator of the Veterans Administration. Address correspondence to Dr. Fraser, Veterans Administration Medical Center (111J). 1985

Received for publication 4 January 1985 and in revised form 2 July

The Journal of Clinical Investigation, Inc.

Volume 76, November 1985, 1789-1795 brain is closely coupled to calcium concentration in nerve cells. Evidence suggests that calcium transport across these membranes precedes the release of neurotransmitter substances in the brain (3). The mechanisms by which this interrelationship is maintained was first described in squid axon (3). Since then, numerous attempts have been made to elucidate the exact mechanisms by which calcium is accumulated and released by nerve endings. These studies were performed both in vivo (4-7) and in vitro $(8-11)$. Because of the difficulty of directly measuring calcium transport in the brain of mammalian species, recent work in calcium transport has been performed in in vitro models called synaptosomes.

Synaptosomes are membrane vesicles that are formed from the presynaptic nerve terminals in the brain (12). During homogenization of cerebral cortex, the presynaptic nerve endings are sheared off and resealed to form intact vesicles called synaptosomes (13-15). Synaptosomes can be used for studies in which vesicles are physiologically oriented (right side out), or in an inverted (inside out) configuration $(8,10,12)$. Many enzymatic and metabolic properties have been demonstrated in synaptosomes $(12,16-18)$, and transport studies with sodium and neurotransmitter substances have also been evaluated. Under these conditions, the synaptosomes have proven to be a reliable and highly reproducible model with which to study alterations in central nervous system function. Synaptosomes contain mitochondria, synaptic vesicles, and endoplasmic reticulum (12), all of which are known to transport calcium in vitro (19-22).

The two major mechanisms by which calcium is transported in synaptosomes are the same as those recognized in squid axon. The first of these is by the $\mathrm{Na}^{+}-\mathrm{Ca}^{++}$exchange mechanism and the second is by an ATP-dependent calcium transport process (10). In squid axons, these transport mechanisms are such that they actively extrude calcium against a very high calcium concentration gradient. Calcium transport by the $\mathrm{Na}^{+}-\mathrm{Ca}^{++}$exchange mechanism occurs as a result of the sodium concentration gradient. Under these conditions, calcium is transported in a direction opposite to that of the sodium movement (23) and the larger the sodium gradient, the greater the amount of calcium which will be exchanged for sodium. The stoichiometry for this uptake process is such that three sodiums are exchanged for each calcium transported. Although $\mathrm{Na}^{+}-\mathrm{Ca}^{++}$exchange has been shown to participate in both influx and efflux of calcium in synaptosomes, ATP-dependent calcium transport occurs only from the cytosolic surface of the synaptosomes, and this occurs only in inverted plasma membrane vesicles $(5,24-26)$. However, calcium transport by the $\mathrm{Na}^{+}-\mathrm{Ca}^{++}$exchanger occurs in both inverted and right side out vesicles (10).

In this study we used both these well established modes of calcium transport to investigate calcium uptake in both normal and uremic synaptosomes. The study was designed to evaluate calcium transport in uremic synaptosomes as compared with normal, as well as to understand the possible mechanisms and functional significance of the observed elevated brain calcium in uremia. 


\section{Methods}

\section{General}

All experiments were performed on 200-g male Sprague-Dawley rats and were carried out in paired groups of normal with blood urea nitrogen $=15 \mathrm{mg} / \mathrm{dl}$ and uremic (blood urea nitrogen $=250 \mathrm{mg} / \mathrm{dl}$ ) animals. The rats were made acutely uremic by performing bilateral ureteral ligation under general anesthesia (ketamine, $150 \mathrm{mg} / \mathrm{kg}$ of body weight, administered intramuscularly). They were then placed in cages and fed regular rat chow with free access to water along with the normal control groups of rats. At $\sim 45 \mathrm{~h}$ of uremia, the rats were killed by decapitation and their forebrain removed and immediately placed in ice-cold isolation media containing $320 \mathrm{mM}$ sucrose, $0.2 \mathrm{mM} \mathrm{K}$-EDTA, $5 \mathrm{mM}$ Tris- $\mathrm{HCl}$, $\mathrm{pH} 7.4$, at $0^{\circ}-4^{\circ} \mathrm{C}$. The normal and uremic rat brains were processed simultaneously. For each group, four rat brains were pooled for isolation of synaptosomes. All further experiments were carried out at $0-4^{\circ} \mathrm{C}$.

Isolation of synaptosomes. Synaptosomes were prepared by a modification of the method of Gray and Whittaker (14), as previously described by our laboratory (12). The brains were first minced with scissors and rinsed thoroughly with isolation media to remove any blood. It was then homogenized in isolation media with a glass Dounce homogenizer and centrifuged at $1,300 \mathrm{~g}$ to remove the heavy fractions. The lighter fraction, consisting of the crude synaptosomal-mitochondrial suspension, was purified by centrifugation on a discontinuous Ficoll gradient with a Beckman ultra-centrifuge (12). At the end of the spin, the synaptosomal fraction was removed by suction with a plastic disposable pipette and stored in isolation media at $-70^{\circ} \mathrm{C}$. The frozen synaptosomes are then able to be used for transport studies after thawing (12).

Protein determination. Protein concentration was determined as previously described (27). The extraction method yielded $\sim 100 \mathrm{mg}$ of synaptosomal protein per $4 \mathrm{~g}$ of rat brain cerebral cortex.

Total internal synaptosomal volume. This was determined by the method previously described by Padan and associates (28). ${ }^{14} \mathrm{C}$-Methoxy inulin was used to measure the external space and tritiated $\mathrm{H}_{2} \mathrm{O}$ was used to determine the total pellet water. Internal volume during experimental conditions were also assessed using tritiated mannitol, which was used as a marker for intracellular water (12). The amount of tritium taken up by the synaptosomes was counted simultaneously with ${ }^{45} \mathrm{Ca}^{++}$ at the end of the experiments. Intrasynaptosomal volume was then compared between normal and uremic synaptosomes.

Oxygen consumption study. Synaptosomal oxygen consumption studies were carried out using a Clark type oxygen electrode at $25^{\circ} \mathrm{C}$ in a manner similar to that of Booth and Clark (29). The incubation media contained $3.0 \mathrm{ml}$ of $100 \mathrm{mM} \mathrm{NaCl}, 75 \mathrm{mM}$ mannitol, $25 \mathrm{mM}$ sucrose,

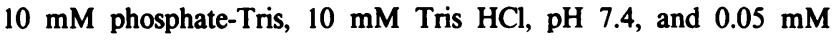
$\mathrm{K}$-EDTA, to which was added $10 \mu \mathrm{l}$ of synaptosomal protein $(\sim 100 \mu \mathrm{g}$ protein) together with $10 \mu \mathrm{l}$ of $10 \mathrm{mM}$ glucose as substrate. Oxygen consumption by the synaptosomes was then calculated on the basis of both the temperature at which the assay was performed and on the protein concentration.

Enzyme assay. Mitochondrial contamination studies were performed at $25^{\circ} \mathrm{C}$ at a wavelength of $550 \mathrm{~nm}$ using a Gilford recording spectrophotometer (model 240). Rotenone insensitive NADH and NADPH cytochrome $c$ reductase activities were measured by modification of the method described by Duncan and Mackler (30). The reaction mixture consisted of $3 \mathrm{ml}$ of $0.3 \mathrm{mM} \mathrm{KCN}, 0.10 \mathrm{mM} \mathrm{NADH}, 0.1 \mathrm{mM}$ NADPH, $0.1 \mathrm{mM}$ cytochrome $c, 1.5 \mathrm{mM}$ rotenone, and $50 \mathrm{mM} \mathrm{K}_{2} \mathrm{HPO}_{4}$ buffer at $\mathrm{pH} 7.4$, to which $10 \mu \mathrm{l}$ of synaptosomal protein was added. The extinction coefficient of cytochrome $c$ was taken to be 21.1 (31).

Lactate dehydrogenase (LDH) ${ }^{1}$ activity was measured by following NADH oxidation at a wavelength of $340 \mathrm{~nm}$ in a medium containing $40 \mathrm{mM}$ potassium phosphate buffer at $\mathrm{pH} 7.4,1 \mathrm{mM}$ pyruvate, $0.2 \mathrm{mM}$ $\mathrm{NADH}$, and $0.5 \%$ Triton X-100 (32). The extinction coefficient of NADH was taken to be $6.22(33)$. Assay was carried out at $25^{\circ} \mathrm{C}$.

1. Abbreviations used in this paper: ER, endoplasmic reticulum; LDH, lactate dehydrogenase; PTH, parathyroid hormone.
$\mathrm{Na}$-Ca exchange assay. By this method, calcium uptake studies were started by removing $0.5-\mathrm{ml}$ aliquots of synaptosomal protein from storage. The protein was allowed to thaw rapidly at room temperature and then incubated for $10 \mathrm{~min}$ in $2 \mathrm{ml}$ of preequilibrium media at $37^{\circ} \mathrm{C}$ in a manner similar to that described by Fraser and associates (12). The preequilibration media consisted of $140 \mathrm{mM} \mathrm{NaCl}, 1 \mathrm{mM} \mathrm{MgSO}_{4}, 10 \mathrm{mM}$ glucose, and $5 \mathrm{mM}$ Hepes-Tris at $\mathrm{pH}$ 7.4. The suspension was then centrifuged at $20,000 \mathrm{~g}$ for $5 \mathrm{~min}$ and the resulting pellet was resuspended and spun at the same speed and for the same duration. At the end of this second spin, the final pellet was resuspended in $400 \mu$ l of the same preequilibration media and stored at $0^{\circ}-4^{\circ} \mathrm{C}$ until they were used for transport studies.

Calcium uptake was initiated by adding $5 \mu \mathrm{l}$ of synaptosomal suspension ( $\sim 50 \mu \mathrm{g}$ protein) to $95 \mu \mathrm{l}$ of external media, which then constituted the reaction mixture. The external media contained $140 \mathrm{mM}$ $\mathrm{KCl}, 1 \mathrm{mM} \mathrm{MgSO}_{4}, 10 \mathrm{mM}$ glucose, $10 \mu \mathrm{M} \mathrm{CaCl}_{2}, 0.1 \mu \mathrm{Ci}^{45} \mathrm{Ca}^{++}$, and $5 \mathrm{mM}$ Hepes-Tris, $\mathrm{pH} 7.4$, at $25^{\circ} \mathrm{C}$. In some experiments, A23187 (a calcium ionophore) was also added to the external media. After the desired periods of incubation, uptake was terminated by adding to the reaction mixture $2 \mathrm{ml}$ of ice-cold $150 \mathrm{mM} \mathrm{KCl}$ solution (stop solution). The mixture was then immediately vacuum filtered through a $0.45-\mu \mathrm{m}$ pore size cellulose-acetate membrane and washed twice with $2 \mathrm{ml}$ of the icecold stop solution. The filters were then dissolved in phase combine II scintillant and counted by a Packard counter (model 2409). Each time point was done in triplicate. The zero time points were obtained by adding $2 \mathrm{ml}$ of the stop solution to $95 \mu \mathrm{l}$ of the external media, and to this mixture was added $5 \mu \mathrm{l}$ of synaptic vesicles ( $\sim 50 \mu \mathrm{g}$ protein) after the reaction was stopped. The mixture was filtered and counted as above. Nonspecific binding of calcium to the protein and filter at time zero was $20 \%$ of the 5-s uptake value. In some experiments, depending on experimental protocol, potassium chloride in the external media was replaced with either ammonium chloride, sodium chloride, rubidium chloride, choline chloride, or lithium chloride in the same concentration as shown above.

ATP-dependent calcium uptake assay. In these experiments, the synaptosomes were loaded with preequilibration media containing $140 \mathrm{mM}$ $\mathrm{KCl}, 1 \mathrm{mM} \mathrm{MgSO}_{4}, 10 \mathrm{mM}$ glucose, and $5 \mathrm{mM}$ Hepes-Tris, pH 7.4, at $25^{\circ} \mathrm{C}$, as discussed previously. $5 \mu \mathrm{l}$ of synaptosomes ( $\sim 50 \mu \mathrm{g}$ protein) were then added to $95 \mu \mathrm{l}$ of external media and allowed to incubate at $25^{\circ} \mathrm{C}$ for the desired time period. The external media contained 140 $\mathrm{mM} \mathrm{KCl}, 1 \mathrm{mM} \mathrm{MgSO}, 10 \mathrm{mM}$ glucose, $1 \mathrm{mM}$ Tris-ATP, $10 \mu \mathrm{M}$ $\mathrm{CaCl}_{2}, 0.5 \mu \mathrm{Ci}^{45} \mathrm{Ca}^{++}$, and $5 \mathrm{mM}$ Hepes-Tris at $\mathrm{pH}$ 7.4. Calcium uptake was terminated at the appropriate time of incubation by diluting the reaction mixture with $2 \mathrm{ml}$ of stop solution. This mixture was then filtered through a cellulose acetate membrane, washed twice with a $150-\mathrm{mM}$ $\mathrm{KCl}$ solution, and counted as discussed above.

\section{Materials}

The chemicals used in these experiments were obtained from the following sources. ${ }^{45} \mathrm{Ca}^{++},{ }^{3} \mathrm{H}_{2} \mathrm{O}$, [methoxy- ${ }^{14} \mathrm{C}$ ]inulin, and $\left[{ }^{3} \mathrm{H}\right]$ mannitol were obtained from New England Nuclear (Boston, MA). Tris-ATP, A23187, Ficoll, rotenone, EGTA, and EDTA were obtained from Sigma Chemical Co. (St. Louis, MO). Cellulose acetate filters, type SM 111-P12, were obtained from Sartorius Filters (Hayward, CA). Sprague-Dawley rats were obtained from Bainton-Kingman (Fremont, CA). All other chemicals were of reagent grade and were obtained from Sigma Chemical Company.

\section{Results}

Total internal volume. The internal volume of both normal and uremic synaptosomes were measured before freezing at $-70^{\circ} \mathrm{C}$. No difference was found in the volumes between both groups of synaptosomes. The values of $3.5 \pm 0.6 \mu \mathrm{l} / \mathrm{mg}$ protein and $3.4 \pm 0.4 \mu \mathrm{l} / \mathrm{mg}$ protein were similar to those obtained by other 
investigators (34). During the various transport experiments, tritiated mannitol was used to assess internal volume. Uptake in both the normal and uremic synaptosomes suggested similar volumes (12).

Enzyme assay. The results of the degree of contamination of the synaptosomal fraction by free mitochondria and endoplasmic reticulum (ER) were evaluated as described in Methods. In this experiment, the activity of both rotenone-insensitive $\mathrm{NADH}$ and NADPH cytochrome $c$ reductase were used as markers. The NADH-cytochrome $c$ reductase is a marker for both the outer mitochondrial membrane and the $\operatorname{ER}(35,36)$, whereas the NADPH-cytochrome $c$ reductase is a specific marker only for the ER (35). In this assay, values for NADH-cytochrome $c$ reductase in normal and uremic synaptosomes were $3.3 \pm 0.4$ vs. $3.5 \pm 0.3 \mathrm{nmol} / \mathrm{min}$ per $\mathrm{mg}$ protein, respectively (12). Values for NADPH-cytochrome $c$ reductase activity in normal and uremic synaptosomes were $0.7 \pm 0.1$ vs. $1.1 \pm 0.3 \mathrm{nmol} / \mathrm{min}$ per mg protein, respectively (12). Therefore, the difference between the two enzyme markers and the measured value of 42.0 $\mathrm{nmol} / \mathrm{mg}$ protein of rotenone-insensitive NADH-cytochrome $c$ reductase for pure mitochondria allows us to calculate the degree of contamination by free mitochondria. This calculation shows that there are $\sim 6.4$ and $5.7 \%$ contamination of the normal and uremic synaptosomes, respectively, with free mitochondria. These values are consistent with those published by other investigators (16). Additionally, we evaluated contamination by ER in normal and uremic synaptosomes. Based on the values for NADPH-cytochrome $c$ reductase in normal and uremic synaptosomes, and the value of $16.0 \mathrm{nmol} / \mathrm{mg}$ protein obtained from a pure ER preparation, the degree of contamination by $\mathrm{ER}$ in normal and uremic synaptosomes are quite small and not significantly different from each other ( 5 vs. 7\%, respectively).

The integrity of the synaptosomal plasma membrane was evaluated by measuring LDH activity, which is a cytosolic marker (37). This was achieved by assaying LDH activity in the absence and presence of the detergent Triton X-100. As shown previously (12), specific activities of LDH in the absence of Triton $\mathrm{X}-100$ were found to be $136 \pm 15.0 \mathrm{nmol} / \mathrm{min}$ per $\mathrm{mg}$ protein and $150 \pm 15 \mathrm{nmol} / \mathrm{min}$ per $\mathrm{mg}$ protein in normal and uremic synaptosomal fractions, respectively. These values increased to $995 \pm 35 \mathrm{nmol} / \mathrm{min}$ per $\mathrm{mg}$ protein and $920 \pm 40 \mathrm{nmol} / \mathrm{min}$ per $\mathrm{mg}$ protein, respectively, in the presence of $0.5 \%$ Triton $\mathrm{X}-100$. The sixfold increase of LDH activity after lysis of the synaptosomes demonstrates an intactness of both groups of synaptosomes before lysing with detergent.

Oxygen consumption. In both normal and uremic synaptosomes, the respiratory rates are not significantly different from each other $(4.3 \pm 0.12 \mathrm{nmol} / \mathrm{min}$ per $\mathrm{mg}$ protein vs. $4.6 \pm 0.2$ $\mathrm{nmol} / \mathrm{min}$ per mg protein, respectively). This similarity in rate of respiration was also observed in the presence of other substrates, such as glucose, ADP, and succinate, a substrate for both mitochondrial and synaptosomal respiration $(14,36)$.

$\mathrm{Na}-\mathrm{Ca}$ exchange in synaptosomes. The experiment in Fig. 1 was designed to evaluate calcium uptake in synaptosomes in the presence of various cations in the external media. As described in Methods, uptake was carried out in the presence of $140 \mathrm{mM}$ of each of the following salts: $\mathrm{RbCl}, \mathrm{KCl}, \mathrm{NH}_{4} \mathrm{Cl}$, choline chloride, $\mathrm{LiCl}$, and $\mathrm{NaCl}$. The aim of this experiment was to compare our findings with those obtained by other investigators (25), and to observe how the sodium-calcium exchange mechanism is influenced by the external ionic concentration. The graph in this figure shows calcium uptake in nanomoles per

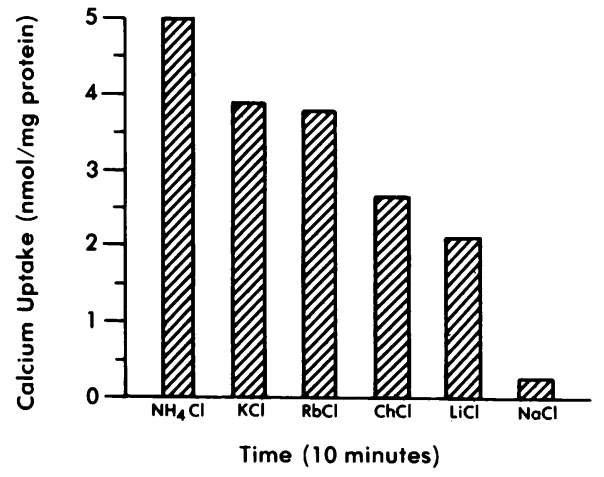

Figure 1. Effects of cations on sodium-calcium exchange mechanism. Synaptosomes were loaded with $140 \mathrm{mM} \mathrm{NaCl}$ media. The external media contained either of the following in a similar concentration $\left(\mathrm{NH}_{4} \mathrm{Cl}, \mathrm{KCl}, \mathrm{RbCl}, \mathrm{ChCl}, \mathrm{LiCl}, \mathrm{NaCl}\right)$. Calcium uptake varied according to sodium gradient and permeability of synaptosomal membrane to ionic solution. This graph is a mean of five experiment and each time point was done in triplicate.

milligrams protein plotted at $10 \mathrm{~min}$. Uptake was evaluated over $15 \mathrm{~min}$ and the relationship in uptake between the various ionic compositions was similar to that shown in Fig. 1 throughout the period of observation. The first conclusion to be drawn from this graph is that without a sodium concentration gradient which is inversely proportional to the calcium concentration gradient, calcium transport will not proceed. When the vesicles were loaded with $140 \mathrm{mM} \mathrm{NaCl}$ and uptake was carried out in the same media, no significant calcium uptake was observed. This suggested that the binding of calcium to these synaptosomes is probably insignificant. On the other hand, when uptake was carried out in the presence of either $\mathrm{NH}_{4} \mathrm{Cl}, \mathrm{KCl}$, or $\mathrm{RbCl}$ in the external media, calcium uptake was markedly enhanced. The synaptosomal membrane is quite permeable to ammonium chloride, potassium chloride, and rubidium chloride. Thus, it appears that the rate of calcium uptake by this mechanism may be related to the relative permeability of the membranes to the major ionic constituents in the external media (38). These vesicles are less permeable to both choline chloride and lithium chloride than to $\mathrm{NH}_{4} \mathrm{Cl}, \mathrm{KCl}$, and $\mathrm{RbCl}$, and they also facilitated less uptake of calcium. From these data we decided to use potassium chloride in the external media in all subsequent sodium-calcium uptake experiments. This experiment was performed in both normal and uremic synaptosomes and the uptake pattern was similar in both groups. Calcium uptake was greater in uremic than in normal synaptosomes in all the conditions studied.

The graph in Fig. 2, shows data for calcium uptake via the $\mathrm{Na}-\mathrm{Ca}$ exchange mechanism in both normal and uremic synaptosomes. The two curves at the bottom of the figure show calcium uptake in both normal and uremic synaptosomes in the presence of the calcium ionophore A23187. The lower of the two curves represents uptake in normal synaptosomes. The ionophore serves to equilibrate calcium concentration inside and outside the vesicles, thus diminishing the ability of the synaptosomes to actively accumulated calcium. However, in the absence of A23187, both groups of synaptosomes rapidly accumulated calcium in exchange for sodium. This is depicted by the two top curves in Fig. 2 that show calcium uptake in normal (closed circle) and uremic (closed triangle) synaptosomes. As is shown by these curves, uptake progressed quite rapidly and reached a maximum value by $5 \mathrm{~min}$ and remained relatively 


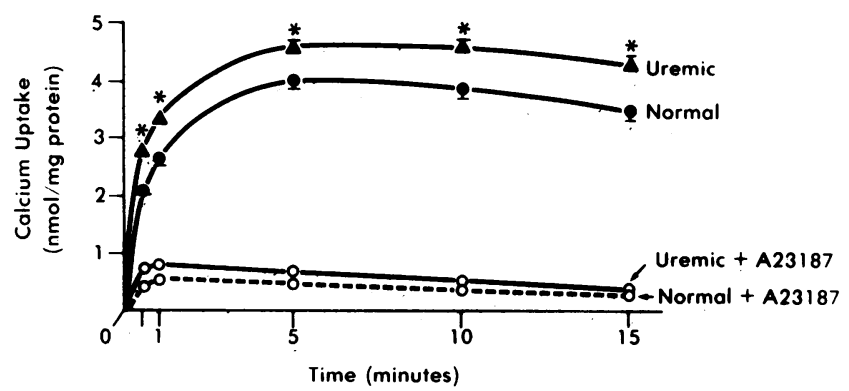

Figure 2. Sodium-calcium exchange in normal vs. uremic synaptosomes. The top curve represented by $\Delta$ shows calcium uptake in uremic synaptosomes. The curve represented by $\bullet$ shows uptake in normal synaptosomes. The curves represented by $O$ and ... represent calcium uptake in the presence of the calcium ionophore A23187. This graph is mean of eight experiments and each time point was done in triplicate. The result is expressed as mean \pm SE. The points indicated by the asterisk represent differences that are significant to $P<0.005$.

constant over the period of observation. It is clear from this graph that calcium accumulation in uremic synaptosomes (top curve) was greater than that observed in normal. This difference was significant to $P<0.005$ throughout the course of observation. In uremic synaptosomes, maximum calcium uptake at $10 \mathrm{~min}$ was $4.60 \pm 0.3 \mathrm{nmol} / \mathrm{mg}$ protein vs. $3.8 \pm 0.3 \mathrm{nmol} / \mathrm{mg}$ protein in normal.

Two possible mechanisms could explain the observed increase in calcium accumulation in uremic synaptosomes. Firstly, there could be a decreased rate of efflux of calcium from the uremic synaptosomes. Secondly, the increased calcium accumulation in uremia could be due to an increased rate of calcium uptake in uremic synaptosomes. To evaluate the rate of uptake of calcium by synaptosomes, we measured initial rate of calcium uptake in both groups of synaptosomes by the sodium-calcium exchange mechanism.

Fig. 3 shows calcium uptake in both normal and uremic synaptosomes between 0 and $30 \mathrm{~s}$. As early as $5 \mathrm{~s}$ after transport was initiated, calcium uptake in uremic synaptosomes was measurably greater than in normal. Additionally, this increase in calcium uptake in uremic synaptosomes was significantly greater

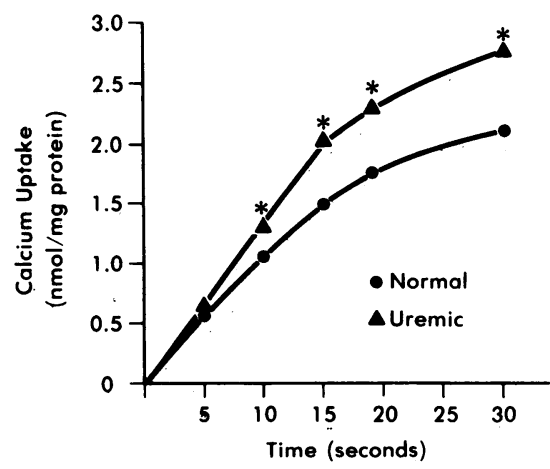

Figure 3. Initial calcium uptake by sodium-calcium exchange mechanism in normal and uremic synaptosomes. The top curve (A) shows uptake in uremic synaptosomes, whereas the bottom curve (•) shows calcium uptake in normal synaptosomes. Uptake in uremia was significantly different $(P<0.005)$ at the points indicated by asterisk. Graph is a mean of eight experiments. than that in normal $(P<0.005)$ as early as $10 \mathrm{~s}$ after uptake was started. This suggests that at least part of the explanation for the difference in calcium accumulation between normal and uremic synaptosomes may be due to increased membrane permeability of uremic synaptosomes to calcium.

ATP-dependent calcium uptake in synaptosomes. By this mechanism of calcium transport, uptake was observed in inverted plasma membrane vesicles only. Hence, the energy source required for this transport process had to be supplied externally. As described in the Methods section, 1.0 mM ATP was used as the source of energy in this experiment.

The reaction was carried out over $15 \mathrm{~min}$ and calcium uptake was measured in nanomoles per milligrams protein (Fig. 4). Three conditions for calcium uptake were evaluated in both groups of synaptosomes. Uptake was measured in the presence of ATP, in the absence of ATP (control), and in the presence of calcium ionophore A23187 in addition to ATP. The bottom curve shows uptake in normal and uremic synaptosomes in the presence of A23187. In this instance, no significant stimulation of calcium uptake was observed, since the ionophore serves to equilibrate calcium concentration inside the synaptosomes with that of the external concentration. Without ATP (second curve from bottom) in the external media, a maximum uptake of only $0.3 \mathrm{nmol} / \mathrm{mg}$ protein was reached, approximately twice that which is observed in the presence of A23187. This suggests that only a small amount of calcium is taken up by the vesicles in the absence of ATP. Both these uptake patterns are similar in both their distribution and magnitude in normal and uremic synaptosomes.

In the presence of ATP (top two curves of Fig. 4), both the rate and the magnitude of calcium uptake achieved by the normal and uremic synaptosomes were markedly increased over control. Additionally, calcium uptake in synaptosomes obtained from uremic rats was significantly greater $(13.0 \mathrm{nmol} / \mathrm{mg}$ protein vs. $10.3 \mathrm{nmol} / \mathrm{mg}$ protein, respectively, $P<0.005$ ) than in normal. Not only was the net accumulation of calcium in uremia increased, but the rate of accumulation appeared to be increased as well. This increased accumulation of calcium by the ATPdependent calcium transport mechanism in inverted plasma membrane vesicles suggests that decreased efflux of calcium from uremic synaptosomes may not be responsible for the difference

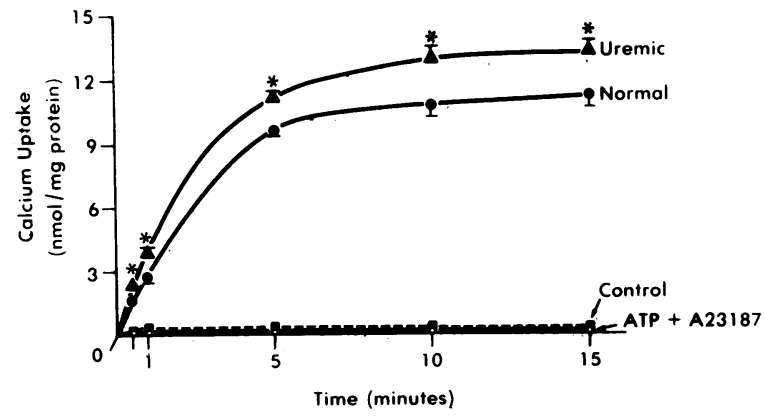

Figure 4. ATP-dependent calcium uptake in normal vs. uremic synaptosomes. The uptake in uremia is shown in the top curve ( $\triangle$ ). Uptake in normal synaptosomes is shown by $\bullet$. Calcium uptake in the presence of calcium ionophore A23187 is represented by $\circ$ in both normal and uremic synaptosomes. The curve represented by $₫$ shows control uptake in the absence of ATP in both groups. The difference was significant to $P<0.005$ at the points indicated by the asterisk. This graph is the mean of eight experiments. Data is expressed as the mean $\pm \mathrm{SE}$. 
in calcium uptake between normal and uremic synaptosomes during $\mathrm{Na}-\mathrm{Ca}$ exchange.

To evaluate possible differences in initial rates of ATP-dependent calcium uptake between both groups of synaptosomes, an experiment was designed to measure calcium uptake at early time points. As shown in Fig. 5, measurements were made between 0 and $30 \mathrm{~s}$. By $15 \mathrm{~s}$ after initiation of the reaction, calcium uptake is shown to be greater in uremia (top curve) than in normal. As was the case in the sodium-calcium exchange experiment, the difference became significant to $P<0.005$ by $15 \mathrm{~s}$ and remained significant throughout the time of observation. This result suggests that calcium transport mediated through the ATP-dependent calcium transport system in synaptic plasma membrane is increased in uremia. Thus, both $\mathrm{Na}-\mathrm{Ca}$ exchange and ATP-dependent calcium transport processes appear to be increased in uremia. Since in vivo both the $\mathrm{Na}-\mathrm{Ca}$ exchange and ATP-dependent calcium transport processes function to extrude calcium from within the cell, both abnormalities would thus tend to favor an increased extracellular calcium concentration in uremia.

The contribution that free mitochondria may have made to calcium uptake by the ATP-dependent transport mechanism was studied by evaluating calcium uptake in the presence of potent mitochondria inhibitors. These include $12 \mu \mathrm{M}$ rotenone, $0.1 \mathrm{mM}$ 2-4-dinitrophenol, $0.1 \mathrm{mM} \mathrm{KCN}, 50 \mu \mathrm{M}$ oligomycin, $0.1 \mathrm{mM}$ azide, and $10 \mu \mathrm{M}$ ruthenium red. No significant change in the relationship between normal and uremic synaptosomal calcium transport was observed (Fig. 6). There were, however, a 5-10\% inhibition of calcium uptake by these inhibitors in both groups.

\section{Discussion}

These data show that there are significant abnormalities of calcium transport in uremic synaptosomes. By investigating the two well-defined mechanisms of calcium transport in synaptosomes $(9,10)$, we were able to demonstrate that $(a)$ there is increased calcium accumulation via the $\mathrm{Na}^{+}-\mathrm{Ca}^{++}$exchange mechanism in uremic synaptosomes, and $(b)$ the influx of calcium into inverted uremic plasma membrane vesicles by the ATP-dependent calcium transport mechanism is increased as well. Investigation of these observations with further studies suggested that there is increased membrane permeability of

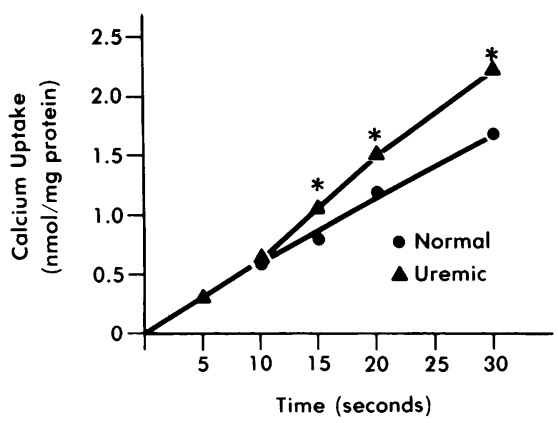

Figure 5. Initial uptake in synaptosomes by ATP-dependent calcium pump. Uptake was carried out between 0 and $30 \mathrm{~s}$. The bottom curve shows calcium uptake in normal synaptosomes (๑), and the top curve (₫) shows uptake in uremic synaptosomes. The points indicated by asterisk are significant to $P<0.005$. Graph is a mean of eight experiments.

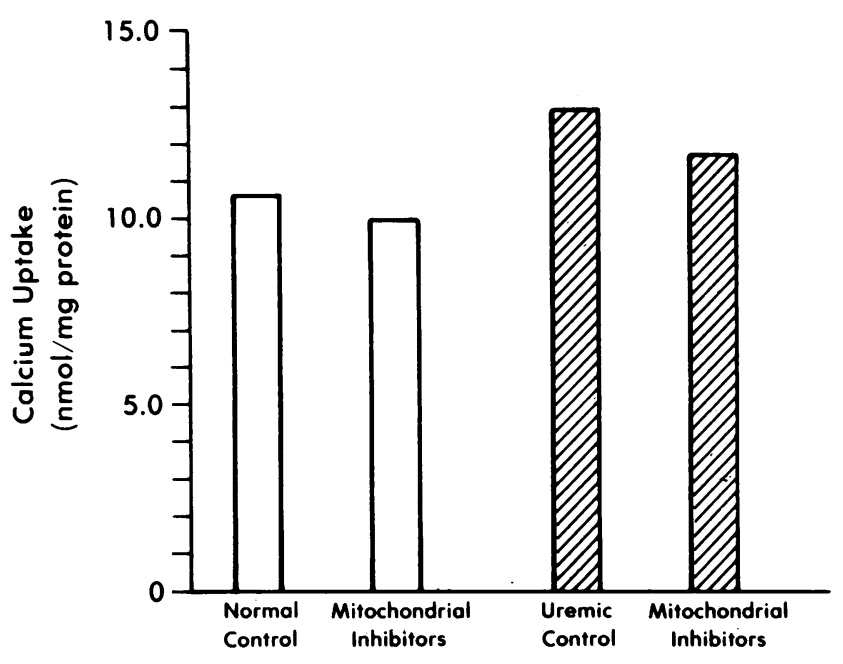

Figure 6. Graph represents ATP dependent calcium uptake in both normal and uremic synaptosomes in the presence and absence of mitochondrial inhibitors. Uptake was carried out in five experiments and measurements were made at ten minutes. Uptake in uremia in the presence of inhibitors was significantly greater than in normal $P$ $<0.005$. Each time point was done in triplicate.

uremic synaptosomes to calcium transport via both $\mathrm{Na}^{+}-\mathrm{Ca}^{++}$ exchange and ATP-dependent calcium transport mechanism. Since both groups of synaptosomes were prepared and stored in a nonuremic environment, it does not appear that these observed abnormalities are due to the uremic sera. An intrinsic defect appears to develop in the membrane of the uremic synaptosomes that is not easily reversible.

Our conclusions are based on the observation that the initial rate of calcium uptake by uremic synaptosomes via the $\mathrm{Na}^{+}-\mathrm{Ca}^{++}$exchange mechanism is significantly greater than in normal synaptosomes $(P<0.005)$. The difference in initial rate of calcium uptake between both groups was seen as early as $5 \mathrm{~s}$ and became significant by $10 \mathrm{~s}$ of uptake (Fig. 3). Calcium uptake in inverted uremic plasma membrane vesicles was also significantly greater than in normal $(P<0.005)$ by $15 \mathrm{~s}$ of uptake (Fig. $5)$, suggesting that the ATP-dependent calcium pump function is increased in uremia. Both these abnormalities in vivo would tend to increase brain extracellular calcium concentration in uremia.

Calcium uptake in synaptosomes via the $\mathrm{Na}^{+}-\mathrm{Ca}^{++}$exchange mechanism occurs in two populations of vesicles simultaneously. One population consists of inverted plasma membrane vesicles, while the other has right side out vesicles. Calcium that is accumulated in inverted vesicles is contained within the vesicles, since the experimental conditions do not facilitate calcium efflux ( $\mathrm{Na}$ in greater than $\mathrm{Na}$ out). On the other hand, the accumulation of calcium within right side out vesicles is quite complex: not only is calcium being accumulated in these vesicles, but calcium is also being effluxed by the ATP-dependent calcium transport mechanism. Native intrasynaptosomal ATP in both normal and uremic synaptosomes is $\sim 0.35 \mathrm{mM}$ (12). These transport processes result in a dynamic steady state where calcium accumulation is a function of rate of calcium influx and rate of efflux by the ATP-dependent calcium pump. Assessment of calcium accumulation by the $\mathrm{Na}^{+}-\mathrm{Ca}^{++}$exchange mechanism, therefore, requires evaluation of rates of influx and of efflux of calcium by the different mechanisms involved. Being able to evaluate these 
vesicles in an inverted manner is a unique property that these synaptosomes afford us (10). Thus, it is possible to evaluate ATPdependent calcium uptake in inverted (inside out) vesicles, where the active site for ATP-dependent calcium pump is now exposed to ATP that is added to the external media.

Factors that could possibly explain the increased calcium accumulation in uremia include differences in vesicle sizes between normal and uremic synaptosomes and enhanced ability of free mitochondria and ER in the uremic preparation to accumulate calcium. From work done previously in our laboratory (12), we have shown that the total intravescicular volume of normal vs. uremic synaptosomes are not significantly different from each other.

Since mitochondria and ER are intrinsic intracellular organelles of the synaptosomes, we are not overly concerned with the activity of these intravesicular organelles. The extrasynaptosomal or free mitochondria, however, could pose a potential problem because of their known ability to accumulate calcium (39). From the available evidence, brain mitochondria are known to transport calcium by the ATP-dependent process and not by $\mathrm{Na}-\mathrm{Ca}$ exchange. This observation suggests that mitochondria can be eliminated as a possible cause of the increased calcium uptake observed in uremic synaptosomes by the $\mathrm{Na}^{+}-\mathrm{Ca}^{++}$exchange mechanism. As shown previously, there is no significant difference in free mitochondria in both groups of synaptosomes. Also, when $\mathrm{Na}^{+}-\mathrm{Ca}^{++}$exchange was carried out in the presence of high concentration of mitochondria inhibitors $(12 \mu \mathrm{M}$ rotenone, $0.1 \mathrm{mM}$ 2-4-dinitrophenol, $0.1 \mathrm{mM} \mathrm{KCN}, 50 \mu \mathrm{M}$ oligomycin $0.1 \mathrm{mM}$ azide, and $10 \mu \mathrm{M}$ ruthenium red), no change in the magnitude of uptake or the relationship between normal and uremic synaptosomes was observed. These data suggest that the increased calcium uptake by uremic synaptosomes during $\mathrm{Na}^{+}-\mathrm{Ca}^{++}$exchange is not due to mitochondrial calcium accumulation. On the other hand, when mitochondria inhibitors were used in similar concentrations in the ATP-dependent calcium uptake experiments, only a small decrease in uptake was observed (Fig. 6). No change in the relationship in calcium uptake pattern between both normal and uremic synaptosomes was observed, suggesting that the contribution of mitochondria to the increased calcium uptake in uremia is insignificant.

As previously stated, there were only 5 and $7 \%$ contamination by ER of both normal and uremic synaptosomal preparation. Although inhibition of ER function was not attempted, from the similarity of the degree of contamination, it appears unlikely that the differences in calcium transport that we observed was due to ER contamination. It thus appears likely that the difference in calcium uptake we observed was due to an intrinsic defect in the membrane of the uremic synaptosomes. However, the precise contribution which ER makes to the net uptake of calcium in either group is presently unclear.

Parathyroid hormone (PTH) has been shown to be an important factor in the accumulation of calcium observed in uremic brain in vivo $(1,2)$, as well as the EEG abnormalities observed in both uremic dogs and humans $(1,2)$. In the present studies, net synaptosomal calcium uptake in uremia was increased in the absence of exogenously administered PTH. However, based on previous studies in vivo $(1,2)$, PTH is most likely elevated in the uremic rats, thus implying a possible PTH-dependent mechanism. Based on the multiple washes that were performed in these experiments, there is probably little if any circulating PTH remaining. Such findings are quite compatable with recent observations by Mahoney and Arieff (40) and Akmal et al. (41).
It has been shown that there is continued accumulation of calcium in dog brain during 6 mo of chronic renal failure in uremic animals with intact parathyroid function (40). Additionally, in uremic dogs previously parathyroidectomized, there is still an accumulation of calcium in brain, but the amount is less than in dogs with intact parathyroid glands (41). Jayakumar and associates (42) showed that there was a $40 \%$ reduction in calcium uptake via the $\mathrm{Na}-\mathrm{Ca}$ exchange mechanisms in rat renal cortex basolateral membrane vesicles after parathyroidectomy. This decrease in calcium uptake subsequent to parathyroidectomy was reversed by PTH infusion (42). Thus, there are PTH-dependent and PTH-independent mechanisms involved in accumulation of calcium in brain in uremia and in basolateral membrane vesicles in renal cortex. The present study has demonstrated abnormalities in two different calcium transport mechanisms in uremic rat brain synaptosomes. The relationship of these findings to PTH is presently unclear.

In summary, it appears that calcium transport in uremic synaptosomes is altered. This alteration results in increased calcium uptake by both the $\mathrm{Na}^{+}-\mathrm{Ca}^{++}$exchange mechanism and the ATP-dependent calcium transport system in uremic synaptosomes. There are at least three intracellular second messenger systems that are important in the regulation of intracellular metabolism. These are cyclic AMP, cyclic GMP, and calcium ion. Intracellular calcium is important in the regulation of lysosomal enzyme release, mitosis, thermogenesis, glucose metabolism, and steroid synthesis, as well as neurotransmission (43). The demonstrated in vitro abnormalities of intracellular calcium flux in the uremic central nervous system may in fact lead to alterations in any of the above mentioned processes in vivo. Since there is no difference in native intravesicular ATP between normal and uremic synaptosomes (12), the difference in calcium efflux via the ATP pump cannot be explained by differences in the available energy source. These findings in our experimental model are consistent with the clinical observation that as early as $24 \mathrm{~h}$ after the onset of acute renal failure, brain calcium is increased and the electroencephalogram is abnormal (2).

\section{Acknowledgments}

The authors thank Ms. Velma Tyler for her assistance in the preparation of this manuscript.

This research was supported by grants AM 28127 from the National Institute of Arthritis, Diabetes, Digestive \& Kidney Diseases, Public Health Service, Department of Health and Human Services, and also by the Research Service of the Veterans Administration Medical Center, San Francisco. Dr. Fraser was a National Kidney Foundation Research Fellow and is presently an Associate Investigator of the Veterans Administration.

\section{References}

1. Guisado, R., A. I. Arieff, and S. G. Massry. 1975. Changes in the electroencephalogram in acute uremia: effects of parathyroid hormone and brain electrolytes. J. Clin. Invest. 55:738-745.

2. Cooper, J. D., V. C. Lazarowitz, and A. I. Arieff. 1978. Neurodiagnostic abnormalities in patients with acute renal failure: evidence for neurotoxicity of parathyroid hormone. J. Clin. Invest. 61:1448-1455.

3. Katz, B., and R. Milidi. 1967. The release of acetylcholine from nerve endings by graded electric pulses. Proc. R. Soc. Lond. B. Biol. Sci. 167:23-38.

4. Baker, P. F., M. P. Blaustein, A. L. Hodgkin, and R. A. Steinhart. 1969. The influence of calcium on sodium efflux in squid axon. J. Physiol. (Lond.). 200:431-458. 
5. DiPolo, R. 1977. Characterization of the ATP-dependent calcium efflux in dialyzed squid axons. J. Gen. Physiol. 69:795-814.

6. Blaustein, M. P. 1977. Effects of internal and external cations and of ATP on sodium-calcium and calcium-calcium exchange in squid axons. Biophys. J. 20:79-111.

7. DiPolo, R., R. Requewa, F. J. Brinley, L. J. Mullins, A. Scarpa, and T. Tiffert. 1976. Ionized calcium concentration in squid axons. $J$. Gen. Physiol. 67:433-467.

8. Akerman, E. O. A., and D. G. Nichols. 1981. Calcium transport by intact synaptosomes. Eur. J. Biochem. 115:67-73.

9. Coutinho, O. P., A. P. Carvalho, and C. A. M. Carvalho. 1983. Effect of monovalent cations on sodium-calcium exchange and ATPdependent calcium transport in synaptic plasma membranes. $J$. Neurochem. 41:670-676.

10. Gill, D. L., E. F. Grollman, and L. D. Kohn. 1981. Calcium transport mechanisms in membrane vesicles from guinea pig brain synaptosomes. J. Biol. Chem. 256:184-192.

11. Requena, J., and L. J. Mullins. 1979. Calcium movement in nerve fibers. $Q$. Rev. Biophys. 12:371-460.

12. Fraser, C. L., P. Sarnacki, and A. I. Arieff. 1985. Abnormal sodium transport in synaptosomes from brain of uremic rats. J. Clin. Invest. 75: 2014-2023.

13. Whittaker, V. P., I. A. Michaelson, R. Jeanette, and A. Kirkland. 1964. The separation of synaptic vesicles from nerve-endings particles (synaptosomes). Biochem. J. 90:293-303.

14. Gray, E. G., and V. P. Whittaker. 1962. The isolation of nerve endings from brain: an electron-microscopic study of cell fragments derived by homogenization and centrifugation. J. Anat. (Lond.). 96:7988.

15. DeRobertis, E. 1967. Ultrastructure and cytochemistry of the synaptic region. Science (Wash. DC). 156:907-914.

16. Whittaker, V. P. 1969. The synaptosome. In Handbook of Neurochemistry, Vol. 2. A. Laltha, editor. Plenum Press, New York. 14: 327-364.

17. Lewis, L. D., U. Ponten, and B. K. Siesjo. 1973. Arterial acidbase changes in unanaesthetized rats in acute hypoxia. Respir. Physiol. 19:312-321.

18. Pastuszko, A., D. F. Wilson, M. Erecinska, and I. A. Silver. 1981. Effects of in vitro and lowered $\mathrm{pH}$ on potassium fluxes and energy metabolism in rat brain synaptosomes. J. Neurochem. 36:116-123.

19. Rahaminoff, H., and R. Spanier. 1979. Sodium dependent calcium uptake in membrane vesicles derived from rat brain synaptosomes. FEBS (Fed. Eur. Biochem. Soc.) Lett. 104:111-114.

20. Schellenberg, G. D., and P. D. Swanson. 1981. Sodium dependent calcium transport by rat brain microsomes. Biochim. Biophys. Acta. 648: 13-27.

21. Javors, M. A., C. L. Bowden, and D. H. Ross. 1981. Kinetic characterization of calcium transport in synaptic membranes. J. Neurochem. 37:381-387.

22. Blaustein, M. P., R. W. Ratzlaff, N. C. Kendrick, and E. S. Schweitzer. 1978. Calcium buffering in presynaptic nerve terminals. $J$. Gen. Physiol. 72:14-41.

23. Blaustein, M. P., and A. L. Hodgkin. 1969. The effect of cynamine on the efflux of calcium from squid axon. J. Physiol. (Lond.). 200:497527.

24. Gill, D. L., S. H. Chueh, and C. L. Whitlow. 1984. Functional importance of the synaptic plasma membrane calcium pump and sodiumcalcium exchanger. J. Biol. Chem. 259:10807-10813.

25. DiPolo, R. 1978. Calcium pump driven by ATP in squid axon. Nature (Lond.). 274:390-392.

26. DiPolo, R., and L. Beague. 1979. Physiological role of ATP driven calcium pump in squid axon. Nature (Lond.). 278:271-273.

27. Lowery, O. H., N. J. Rosenberg, A. L. Farr, and R. J. Randall. 1951. Protein measurements with the Folin-phenol reagent. J. Biol. Chem. 193:265-275.

28. Padan, E., D. Zilberstein, and H. Rottenberg. 1976. The proton electrochemical gradient in escherichia coli cells. Eur. J. Biochem. 63: 533-541.

29. Booth, R. F. G., and J. B. Clark. 1978. A rapid method for the preparation of relatively pure metabolically competent synaptosomes from rat brain. Biochem. J. 176:365-370.

30. Duncan, H. M., and B. Mackler. 1966. Electron transport systems of yeast. J. Biol. Chem. 241:1694-1697.

31. Omura, T., and S. Takesue. 1970. A new method for simultaneous purification of cytochrome b5 and NADPH-cytochrome $\mathrm{c}$ reductase from rat liver microsomes. J. Biochem. 67:249-257.

32. Clark, J. B., and W. J. Nicklas. 1970. The metabolism of rat brain mitochondria. J. Biol. Chem. 245:4724-4731.

33. Bergmeyer, H. U., H. Klotzsch, H. Mollering, M. NelbockHochstetter, and K. Beauchamp. 1965. Section D. Biochemical reagents. In Methods of Enzymatic Analysis. H. U. Bergmeyer, editor. Academic Press, New York. 1011.

34. Deutch, C., C. Drown, U. Rafalowska, and I. A. Silver. 1981. Synaptosomes from rat brain: morphology, compartmentation, and transmembrane pH and electrical gradients. J. Neurochem. 36:20632072.

35. Gurd, J. W., L. R. Jones, H. R. Mahler, and W. J. Moore. 1974. Isolation and partial characterization of rat brain synaptic plasma membranes. J. Neurochem. 22:281-290.

36. Beattie, D. S. 1968. Enzyme localization in the inner and outer membranes of rat liver mitochondria. Biochem. Biophys. Res. Commun. 31:901-907.

37. Johnson, M. K., and V. P. Whittaker. 1963. Lactate dehydrogenase as a cytosolic marker in brain. Biochem. J. 88:404-409.

38. Keen, P., and T. D. White. 1971. The permeability of pinched off nerve endings to sodium potassium and chloride and the effects of gramiciden. J. Neurochem. 18:1097-1103.

39. Nicholls, D. G. 1978. Calcium transport and proton electrochemical potential gradient in mitochondria from guinea-pig cerebral cortex and rat heart. Biochem. J. 170:511-522.

40. Mahoney, C. A., and A. I. Arieff. 1983. Central and peripheral nervous system effects of chronic renal failure. Kidney Int. 24:170-177.

41. Akmal, M., D. A. Goldstein, S. Multani, and S. G. Massry. 1984. Role of uremia, brain calcium, and parathyroid hormone on changes in electroencephalogram in chronic renal failure. Am. J. Physiol. 246(15): F575-F579.

42. Jayakumar, A., L. Cheng, C. T. Liang, and B. Sacktor. 1984. Sodium gradient-dependent calcium uptake in renal basolateral membrane vesicles. J. Biol. Chem. 259(17):10827-10833.

43. Rasmussen, H., and D. B. P. Goodman. 1977. Relationships between calcium and cyclic nucleotides in cell activation: cellular calcium metabolism and calcium-mediated cellular processes. Physiol. Rev. 57: 428-441. 